\title{
Infectious Bursal Disease: Evaluation of Pathogenicity of Commercial Vaccines from Brazil in Specific Pathogen Free Chichens (ERRATA)
}

Author(s)

Moraes HLS ${ }^{1,2}$

Salle CTP ${ }^{1}$

Padilha AP

Nascimento VP1

Souza GF ${ }^{1}$

Pereira RA ${ }^{2}$

Artencio $\mathrm{JO}^{1}$

Salle $\mathrm{FO}^{1}$

Canal $\mathrm{CW}^{1}$

Centro de Diagnóstico e Pesquisa em Patologia Aviária - CDPA/UFRGS

2 Faculdade de Medicina Veterinária da Universidade Luterana do Brasil - ULBRA

3 Faculdade de Medicina Veterinária da Universidade de Passo Fundo - UPF

\section{Mail Address}

Hamilton Luiz de Souza Moraes

Centro de Diagnóstico e Pesquisa em Patologia

Aviária - CDPA/UFRGS

Av. Bento Gonçalves, 8824

Bairro Agronomia

91.540000 - Porto Alegre, RS, Brasil

E-mail: hamilton.souza.moraes@ufrgs.br

\section{Keywords}

Bursa of Fabricius, infectious bursal disease, pathogenicity, vaccines.

\section{Acknowledgements}

Grants to this study were given by Conselho Nacional de Desenvolvimento Científico e Tecnológico (CNPq).

\section{ABSTRACT}

Infectious Bursal Disease (IBD) is a chicken disease economically important for the poultry industry in function of the immune depression that it causes. Disease control is made with different vaccines and vaccination programs. In present work, the pathogenicity of 3 intermediate vaccines (11, 12 and 13$), 2$ intermediate more pathogenic (IP1 and IP2) and 3 vaccines containing strong virus (F1, F2 and F3) was evaluated. Birds vaccinated with IP1, IP2, F1, F2 and F3 showed significantly lower bursa size in relation to control animals and animals vaccinated with 11,12 and 13 . On the other hand, vaccines 11 and 13 induced antibody titers higher than the control and lower than I2, IP1, IP2, F1, F2 and F3. Histological scores showed that vaccines I1, I2 and I3 induced similar injury degree, although 12 and 13 were not different from the control, whereas I1 was slightly different. Strong vaccines induced more pronounced lesions than the other tested vaccines. These findings suggest that strong vaccines are able to cause severe bursal injuries.

However, bursometry and relative weight of the bursa of Fabricius wereconsidered inadequate to evaluate vaccine pathogenicity. Moreover, strong vaccines induced higher antibody titers than the other vaccines, although some intermediate vaccines induced similar titers.

\section{INTRODUCTION}

Infectious Bursal Disease (IBD) is a viral disease that affects mainly young chickens and is economically important to the poultry industry (Van den Berg, 2000). Consequently, several types of vaccines and vaccination programs have been developed in order to prevent this disease. Solano et al. (1986) evaluated the effect of the levels of maternal antibody in chicks on the prime vaccination against IBDV and reported better antibody response when birds were vaccinated at 28 days of age. On the other hand, Kumar et al. (2000) considered 21 days old as the ideal age for vaccination, since maternal antibodies were not detectable anymore and could not interfere with the replication of the vaccine virus. The immunosuppressive effect of IBD on the vaccination against infectious bronchitis was assessed and it was observed that younger birds inoculated with IBDV were generally more susceptible to infectious bronchitis virus than animals inoculated with IBDV at older ages (Pejkovski et al., 1979). Although there is variability in the persistence of maternal antibodies in the progeny, antibody levels at the first day of age can be known according to the breeder immunity, and it is thus possible to estimate antibody half life and establish the most appropriate period for prime vaccination (Alam et al., 2002).

Immune suppression is inversely related to the degree of histological integrity of the Bursa of Fabricius (BF) and also to the age at which it was induced (Iván et al., 2001). Some vaccines are capable of inducing 